\title{
Forming Process and Simulation Analysis of Helical Carbon Fiber Reinforced Aluminum Matrix Composite
}

\author{
Jun Liang, Chunjing Wu *, Zihang Zhao and Weizhong Tang \\ Institute for Advanced Materials and Technology, University of Science and Technology Beijing, \\ Beijing 100083, China; liang790830@163.com (J.L.); zhaozihang02@163.com (Z.Z.); \\ wztang@mater.ustb.edu.cn (W.T.) \\ * Correspondence: cjwu@mater.ustb.edu.cn; Tel.: +86-138-3248-5017
}

check for updates

Citation: Liang, J.; Wu, C.; Zhao, Z.; Tang, W. Forming Process and Simulation Analysis of Helical Carbon Fiber Reinforced Aluminum Matrix Composite. Metals 2021, 11, 2024. https://doi.org/10.3390/ met11122024

Academic Editor: Stefano Spigarelli

Received: 1 November 2021

Accepted: 9 December 2021

Published: 14 December 2021

Publisher's Note: MDPI stays neutral with regard to jurisdictional claims in published maps and institutional affiliations.

Copyright: (c) 2021 by the authors. Licensee MDPI, Basel, Switzerland. This article is an open access article distributed under the terms and conditions of the Creative Commons Attribution (CC BY) license (https:// creativecommons.org/licenses/by/ $4.0 /)$.

\begin{abstract}
In order to promote the industrialization of the large deformation technology of carbon fiber composites, this paper studies a new method of forming of helical carbon fiber reinforced aluminum matrix composite. The purpose is to solve the problem of large deformation of carbon fiber with low elongation and metal matrix with high elongation. By introducing carbon fiber with helical space structure into the aluminum matrix, the helical carbon fiber reinforced aluminum matrix composites were prepared and the subsequent drawing deformation was carried out. Here we systematically studied the large plastic deformation behavior of helical carbon fiber reinforced aluminum matrix composite via a combination of numerical simulations and experiments, and analyzed the deformation law and stress of helical carbon fiber in the deformation process. We found that the plastic deformation of the composite causes local stress concentration around the helical carbon fiber, and the helical carbon fiber will move synchronously with the aluminum matrix during the deformation, and receive the pressure from the aluminum matrix. Second, the best process parameters obtained from the simulation, that is, the drawing die angle $\alpha=7^{\circ}$, when fivepass drawing experiments were carried out, the total deformation reached $58 \%$, and the average elongation of a single pass was $18.9 \%$. The experimental show carbon fiber reinforced aluminum matrix composite with helical space structure can achieve large deformation and high strength. The experimental and simulation are in general agreement, which verifies the correctness of the carbon fiber helical structure model.
\end{abstract}

Keywords: helical carbon fiber; aluminum matrix composite; plastic forming; drawing; finite element simulation

\section{Introduction}

Metal matrix composites (MMCs) are a new type of material that appeared in the 1960s, and have been developing rapidly in the past decade or so [1]. Because of its high specific strength, high specific modulus, good thermal conductivity, good electrical conductivity, low coefficient of thermal expansion, good dimensional stability, good wear resistance, fatigue resistance and other advantages, it is widely used in various fields. It was first developed and applied in aerospace and military [2], including the antenna suspension of the Hubble Space Telescope, the rear spar of the landing gear of the F-16 fighter jet [3] and the protective armor of the C-130 transport aircraft. As the technology matures and advances, new products continue to be developed and applications in transportation, energy, and electronic communications [4] are being rapidly promoted.

In 1953, Davis et al. [5] used the oxide of Fe as a catalyst to crack CO at $450{ }^{\circ} \mathrm{C}$, and two intertwined carbon fibers were observed in the product for the first time by electron microscopy, from which researchers began to study this helical shape of carbon fibers. However, this is a microscopic helical carbon fiber structure that is irregular and has an indeterminate growth direction. What we need is a carbon fiber bundle with a helical structure on a macroscopic scale, and it should be regular in shape and homogeneous 
in structure, and the helical structure should be controllable. Numerous studies have shown that $[3,6]$ the introduction of carbon fiber can significantly improve the mechanical properties of aluminum matrix composites, and the volume fraction of carbon fiber, surface treatment methods, preparation methods and other factors have a great impact on the properties of the material. SHA et al. [7] prepared carbon fiber reinforced aluminum matrix composites by plating the surface of carbon fiber with copper and using the extrusion infiltration method. The measured tensile strength of the material was $140 \mathrm{MPa}$ and the elastic modulus was $82 \mathrm{GPa}$, which was significantly higher than that of the matrix material. In recent years, a lot of research work [8] has been carried out on the secondary processing and forming of carbon fiber composites after molding. Wang et al. [9,10] systematically studied the material removal mechanism of CFRP orthogonal cutting and investigated the effects of tool geometry and cutting parameters on the cutting force and geometry of the machined surface. In addition, some other scholars [11] used finite element analysis to study the mechanism and deformation law of carbon fiber composites during the forming process, etc. [12-14]. Rauchs et al. [15] used finite element method to study the role of residual stresses during the preparation of carbon fiber composites and the frictional force during the crack extension, and found that the hitching fibers could effectively reduce the stress intensity factor at the crack tip and play a role in stopping cracking. Tang et al. [16] used the finite element simulation method to model the mechanical behavior during the multi-pass drawing process, including the intrinsic model of the material, and discussed the convergence problem in the simulation process. The researchers found that the damage evolution during the drawing process showed obvious nonlinear characteristics with the increase of the drawing pass.

Since the elongation of long continuous straight carbon fibers is less than $2 \%$, it is almost impossible for the current straight carbon fiber reinforced aluminum matrix composites to carry out subsequent large plastic deformation, and the application range is somewhat limited. Compared to straight fibers, helical fibers can usually tolerate large elongation while still retaining low strain, due to their geometrical shapes. The helical structure has better toughening ability than the straight carbon fiber structure in guiding crack propagation and stress dispersion [17].

This paper presents a helical carbon fiber-reinforced aluminum matrix composite preparation and forming process, a new method of secondary processing and forming of carbon fiber composite. The key is adding the helical carbon fiber spatial configuration to the aluminum matrix, so that the aluminum and helical carbon fiber composite, which can be subjected to subsequent secondary drawing processing, can achieve the effect of simultaneous elongation deformation of the helical carbon fiber and the aluminum matrix. The effect on the deformation of the composite material (both on the aluminum matrix and on the helical carbon fiber) was investigated by comparing the five-pass drawing with the multi-pass drawing. In this paper, we use ABAQUS finite element analysis simulation software to simulate the composite forming process, design and fabricate the mold used for composite preparation, and verify it experimentally. The deformation law of helical carbon fiber reinforced aluminum matrix composite, which provides an experimental and theoretical basis for the forming process of carbon fiber composite, was analyzed.

\section{Materials and Methods}

\subsection{Removal of Surface Sizing Materials from Carbon Fibers}

When carbon fibers are shipped from the factory, the surface is usually coated with organic epoxy protective adhesive in order to protect the clean and active fiber surface from adsorbing moisture and dust in the air $[18,19]$. In this experiment, PAN-based (T700) carbon fiber produced by Toray, Japan was used, and its main performance parameters are shown in Table 1. 
Table 1. Specifications and properties of carbon fibers.

\begin{tabular}{ccccccc}
\hline Specifications & $\begin{array}{c}\text { Fiber } \\
\text { Diameter/ } \boldsymbol{\mu m}\end{array}$ & $\begin{array}{c}\text { Tensile } \\
\text { Strength/GPa }\end{array}$ & $\begin{array}{c}\text { Elastic } \\
\text { Modulus/GPa }\end{array}$ & $\begin{array}{c}\text { Linear } \\
\text { Density/mg } \cdot \mathbf{m}^{-\mathbf{1}}\end{array}$ & $\begin{array}{c}\text { Bulk } \\
\text { Density/g.cm } \mathbf{c m}^{-3}\end{array}$ & $\begin{array}{c}\text { Elongation at } \\
\text { Break/\% }\end{array}$ \\
\hline T700 & 7 & 4.90 & 230 & 800 & 1.80 & 2.10 \\
\hline
\end{tabular}

In this experiment, a combination of high-temperature burning and acetone soaking was used for carbon fiber surface degumming treatment: holding at $440{ }^{\circ} \mathrm{C}$ for $45 \mathrm{~min}$, after deionized water cleaning, and then soaked in acetone for $40 \mathrm{~min}$, and then cleaned and dried. This process can more completely remove the adhesive layer on the surface of carbon fiber [20-22].

\subsection{Prefabricated Part Preparation}

In order to prepare a carbon fiber-reinforced aluminum matrix composite with a helical spatial configuration, the reinforcing phase prefabricated parts should be made first. On this topic, we propose to prepare a helical carbon fiber prefabricated part, fix the prefabricated part in the casting mold, and obtain the composite material by pouring aluminum liquid.

The carbon fiber of the prefabricated part needs to be wound on the fine aluminum rod according to a certain law. The helical carbon fiber can be regarded as a helix, with a fixed helix diameter, and a fixed pitch is used to wind the carbon fiber. Therefore, the change of helical diameter and pitch before and after processing can be used as the macroscopic performance and judgment basis of deformation law. With a marker, mark the surface of the treated fine aluminum rod with the same pitch, take the pitch as $10 \mathrm{~mm}$, and define it as the nominal pitch. After the above preparatory work was completed, the preparation of prefabricated parts was started. One end of the carbon fiber was fixed to the bottom end of the thin aluminum rod after high temperature desizing, and then the free end was wound around the thin aluminum rod to a sufficient length according to the graduated line to obtain a helical carbon fiber prefabricated part with a fixed pitch and diameter, as shown in Figure 1.

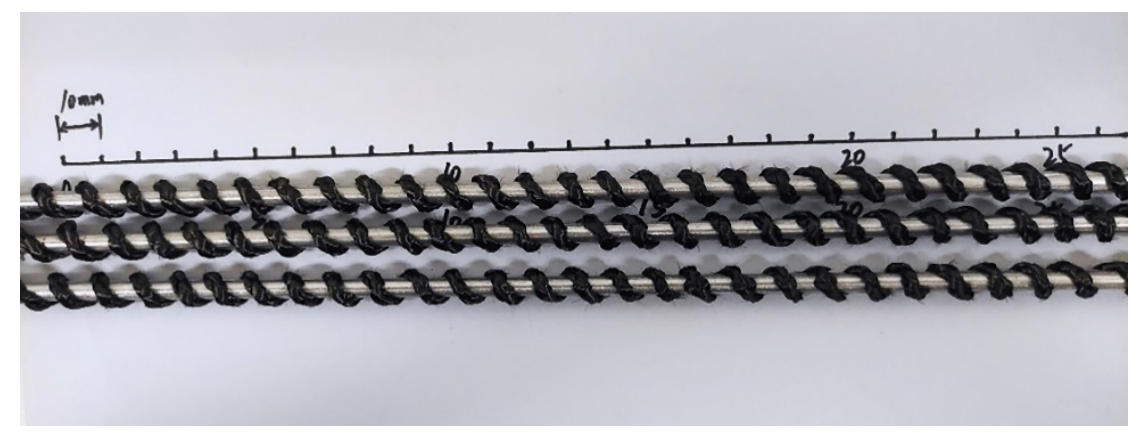

Figure 1. Helical carbon fiber prefabricated parts.

\subsection{Composite Material Preparation}

To prepare helical carbon fiber reinforced aluminum matrix composites, a mold casting process was used in this study. The preheated $\left(420^{\circ} \mathrm{C}\right)$ helical carbon fiber preforms were fixed in the center of a graphite mold, and then the graphite mold was placed in a chamber resistance furnace and preheated to $550{ }^{\circ} \mathrm{C}$. Pure aluminum $(1060,99.6 \%)$ was heated to $800{ }^{\circ} \mathrm{C}$ and held for $30 \mathrm{~min}$. After removing the surface slag, the temperature of molten aluminum liquid is measured by portable thermocouple (pouring temperature is $750{ }^{\circ} \mathrm{C}$ ) and then poured into the preheated graphite mold. The liquid level was kept stable during casting. Casting experiments were performed at standard atmospheric pressure. After cooling, the composite sample was removed from the mold.

For the characteristics of this experiment, a special mold was designed in this study, as shown in Figure 2. The top of the casting is designed for solidification and shrinkage, 
and the bottom of the mold is designed for fixing the spiral carbon fiber prefabricated parts. The size of the hole is determined according to the diameter of the aluminum bar in the center of the prefabricated parts, and a certain size tolerance is given to ensure smooth assembly. In order to reduce the influence of molten aluminum liquid on the preform during pouring, the molten aluminum gradually filled the cavity along the inner wall of the mold during the pouring process, and finally a good quality composite material was obtained. After the casting was completed, the upper riser of the sample was removed to obtain the composite bar billet.

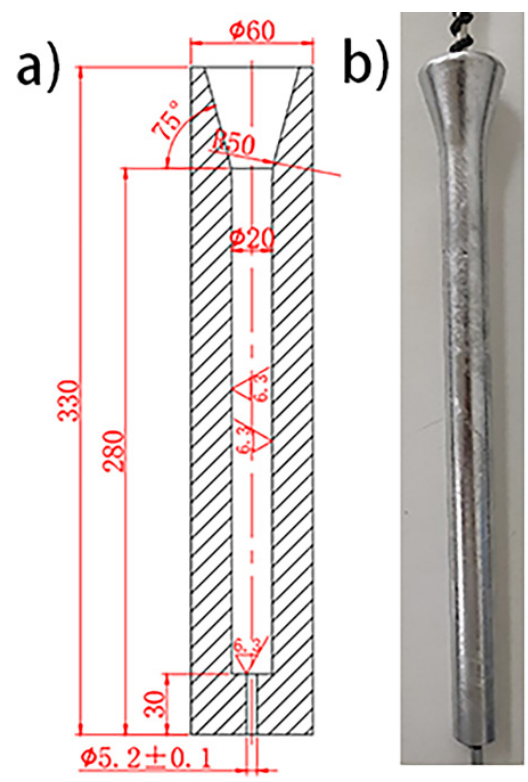

Figure 2. Mold and composite bars: (a) graphite mold; (b) composite bar.

\subsection{Secondary Draw Forming}

The more processing passes, the greater the damage to the carbon fiber [23-25], which reduces the reinforcement effect. Helical carbon fiber will elongate with the deformation of the matrix, when it reaches a certain length, it will not continue to elongate, and will cause fracture damage to the carbon fiber if it continues to deform; thus, the drawing process should also take into account the ultimate elongation of the carbon fiber. The initial length of the experimentally designed composite drawing specimen is $150 \mathrm{~mm}$, which contains 15 pitches of helical carbon fiber bundle, and the length of the carbon fiber bundle can be calculated according to the single helix length formula on the cylinder, as shown in Equation (1).

$$
L=\frac{h}{S} \times\left[(\pi d)^{2}+S^{2}\right]^{\frac{1}{2}}
$$

where, $L$ is the carbon fiber unfolded length, $h$ is the length of the specimen, $S$ is the carbon fiber helical pitch, $d$ is the carbon fiber helical diameter, taking into account the nominal diameter of the carbon fiber $3 \mathrm{~mm}$. However, its soft texture in the winding process can easily become a flattened elliptical, the rope as a helical line. The helical diameter of about $7 \mathrm{~mm}$. can be calculated from the carbon fiber bundle unfolded length $L$.

$$
L=\frac{150}{10} \times\left[(7 \pi)^{2}+10^{2}\right]^{\frac{1}{2}} \approx 362.4 \mathrm{~mm}
$$

The difference between the calculated unfolded length and the actual unfolded length ( $375 \mathrm{~mm}$ ) by the above equation is not significant, and it can be assumed that the actual unfolded length of the designed helical carbon fiber bundle is about $370 \mathrm{~mm}$, which is the theoretical elongation limit of the helical carbon fiber. In the composite, the helical carbon fiber is elongated simultaneously with the aluminum matrix [26]. If the drawing 
elongation of the composite aluminum bar exceeds the theoretical elongation limit of the helical carbon fiber, the helical carbon fiber will fracture.

In the process of drawing plastic processing deformation, according to the principle of volume invariance [27], the overall deformation is calculated first, the maximum length that the composite material can be processed to reach. Since the volume of carbon fiber accounts for a relatively small amount, its influence on the volume is neglected, and all calculations are made with the aluminum matrix. According to the cylindrical volume equation,

$$
V=\frac{1}{4} \pi D^{2} L
$$

then we have,

$$
\frac{1}{4} \pi D_{1}^{2} L_{1}=\frac{1}{4} \pi D_{2}^{2} L_{2}
$$

where $D_{1}$ and $D_{2}$ are the diameters of the composite material before and after drawing, and $L_{1}$ and $L_{2}$ are the lengths of the composite material before and after drawing. According to the tensile length of carbon fiber bundles in prefabricated parts, it is assumed that the length of composite material after drawing is $355 \mathrm{~mm}$, then we have.

$$
\begin{gathered}
\frac{D_{2}{ }^{2}}{D_{1}{ }^{2}}=\frac{L_{1}}{L_{2}}=\frac{150 \mathrm{~mm}}{355 \mathrm{~mm}} \approx 0.4225 \\
D_{2}=D_{1} \times \sqrt{0.4225}=20 \times \sqrt{0.4225}=13 \mathrm{~mm}
\end{gathered}
$$

The diameter after drawing is $D_{2}=13 \mathrm{~mm}$, and $L_{2}=355 \mathrm{~mm}$ is calculated by Equation (4). When designing the drawing process, the carbon fiber integrity should be ensured as much as possible, and the elongation limit of spiral carbon fiber should not be exceeded, and the material processing rate is also considered. A five-pass composite drawing process was designed, and the total processing rate is $58 \%$. Table 2 shows the drawing process parameters.

Table 2. Composite material drawing process parameters.

\begin{tabular}{cccc}
\hline Pass & Diameter/mm & Elongation & Area Reduction/\% \\
\hline 0 & 20 & 0 & 0 \\
1st & 18 & 1.23 & 19 \\
2nd & 16 & 1.27 & 21 \\
3rd & 15 & 1.14 & 12 \\
4th & 14 & 1.15 & 13 \\
5th & 13 & 1.16 & 14 \\
\hline
\end{tabular}

In order to study the influence of the process rate on the deformation of composite materials, this thesis designed a multi-pass drawing based on the adjustment of parameters, such as pass deformation and die angle.

\subsection{Establishment of Geometric Model}

Finite element analysis first requires three-dimensional solid modeling [28,29]. Although ABAQUS software has the pre-processing module CAE, it can only build some 2D and 3D models with regular and simple shapes, and the functions are not powerful enough. This paper involves the complex modeling of helical carbon fiber structures, so with the help of UG NX, a professional 3D modeling software, the 3D helical carbon fiber reinforced aluminum matrix composite material is built. The model was then imported into ABAQUS as a part for post-processing. Since the model does not have axisymmetry, it can only be modeled as a whole, but the material has the characteristic of periodicity in the axial direction. In order to reduce the calculation, the model is selected to have half of the actual dimensional length in the axial direction, and the others are modeled in the same scale, as shown in Figure 3. 


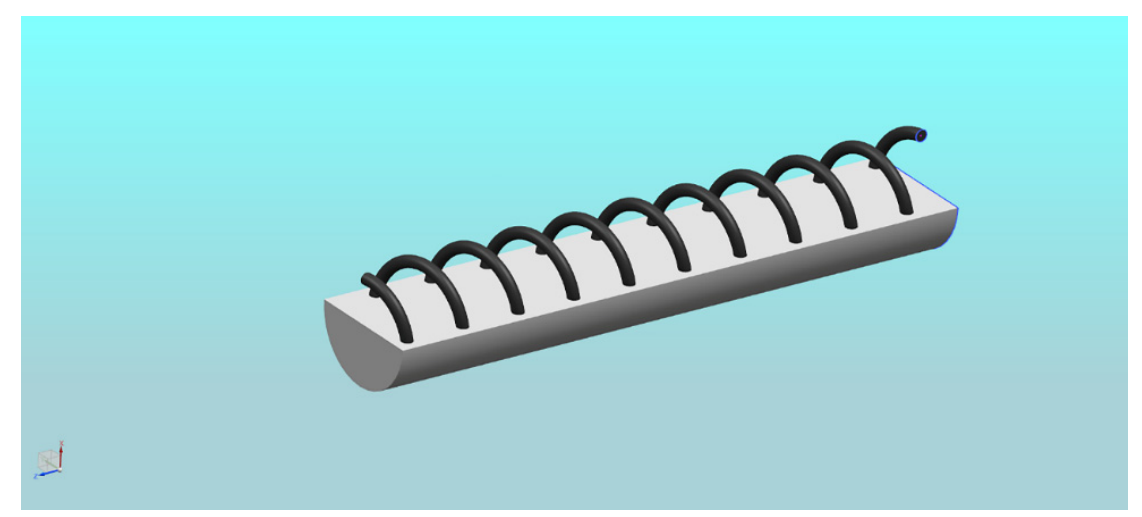

Figure 3. Half section of the 3D model of Al-based helical carbon fiber composite bar.

According to the designed drawing process, a five-pass drawing model is established, and the composite material model is simplified and modeled according to the actual material characteristics. Since the helical carbon fibers are woven from three strands of $12 \mathrm{~K}$ carbon fiber bundles, modeling them according to the actual situation would result in a huge amount of data and too long of a calculation time, so the helical carbon fibers are simplified to a $2 \mathrm{~mm}$ diameter carbon fiber rope. Due to the complexity of the interface between the helical carbon fiber and the aluminum substrate, and the lack of relevant physical parameters for the interfacial behavior caused by microstructural interactions, the model was simplified to a non-metallurgical bonding mode for the interface between the carbon fiber and the aluminum substrate, and the contact boundary conditions were defined by subsequent contact interactions. After the model was established and assembled, the five-pass drawing 3D model is shown in Figure 4.

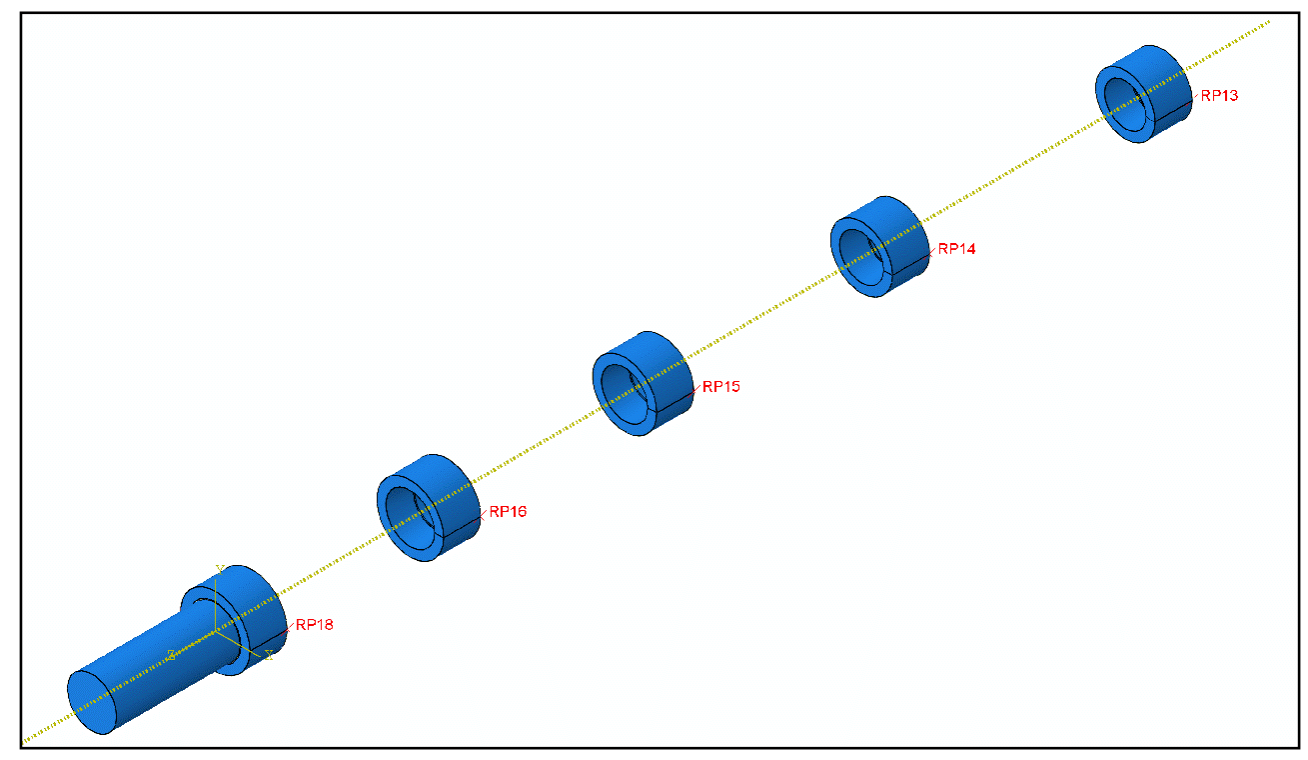

Figure 4. Finite element 3D model of composite material with five-pass drawing.

During the drawing experiments, there are many influencing factors, which all bring different effects on the experimental results, including the drawing speed, deformation degree, drawing method, friction coefficient, lubrication, and die structure during the experiments. The parameters used in numerical calculations and experiments are shown in Table 3. 
Table 3. Parameters used in numerical calculations and experiments.

\begin{tabular}{cc}
\hline Item & Parameter \\
\hline Length of billet $(\mathrm{mm})$ & 110 \\
Diameter of billet $(\mathrm{mm})$ & 20 \\
Preheating temperature of mold $\left({ }^{\circ} \mathrm{C}\right)$ & 550 \\
Total processing rate of drawing $(\%)$ & 58 \\
Drawing speed $(\mathrm{m} / \mathrm{min})$ & 3 \\
Density of Al-based $\left(\mathrm{kg} / \mathrm{m}^{3)}\right.$ & $2.69 \times 10^{3}$ \\
Modulus of elasticity of Al-based $(\mathrm{GPa})$ & 69 \\
Poisson's ratio of Al-based & 0.33 \\
Modulus of elasticity of carbon fiber $(\mathrm{GPa})$ & $\mathrm{E}_{1}=230, \mathrm{E}_{2}=20, \mathrm{E}_{3}=20$ \\
Modulus of shear of carbon fiber $(\mathrm{GPa})$ & $\mathrm{G}_{12}=230, \mathrm{G}_{13}=20, \mathrm{G}_{23}=20$ \\
Poisson's ratio of carbon fiber & $\mu_{12}=\mu_{13}=\mu_{23}=0.32$ \\
Total number of Al-based lattice cells (tetrahedral cells) & 27,866 \\
Total number of carbon fiber lattice cells (hexahedral cells) & 12,309 \\
Mesh density type & Relative \\
Al-based meshing type & Sweeping meshing \\
Carbon fiber meshing type & Free meshing \\
Type of solution & ABAQUS/Explicit \\
\hline
\end{tabular}

\section{Results and Discussion}

\subsection{Numerical Simulation Results}

3.1.1. Analysis of Stress and Strain in the Drawing Deformation of Composite

During drawing, the metal in the deformation zone is in a two-way compressive $\left(\sigma_{\mathrm{r}}, \sigma_{\theta}\right)$ and one-way tensile $\left(\sigma_{1}\right)$ stress state under the action of the drawing force $P$, the positive pressure $N$ given by the die and the frictional force $T$. Since the drawn composite material is a solid circular bar, the stresses are in an axisymmetric stress state (as shown in Figure 5). The deformation state of the metal in the deformation zone is two-way compression $\left(\varepsilon_{\mathrm{r}}, \varepsilon_{\theta}\right)$ and one-way tension $\left(\varepsilon_{1}\right)$.

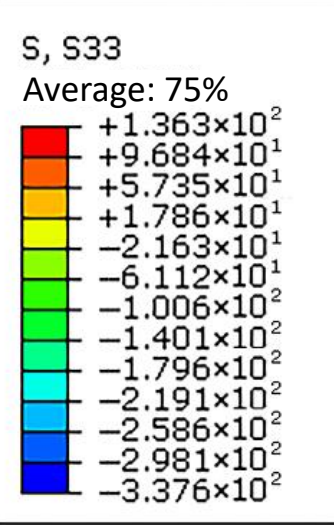

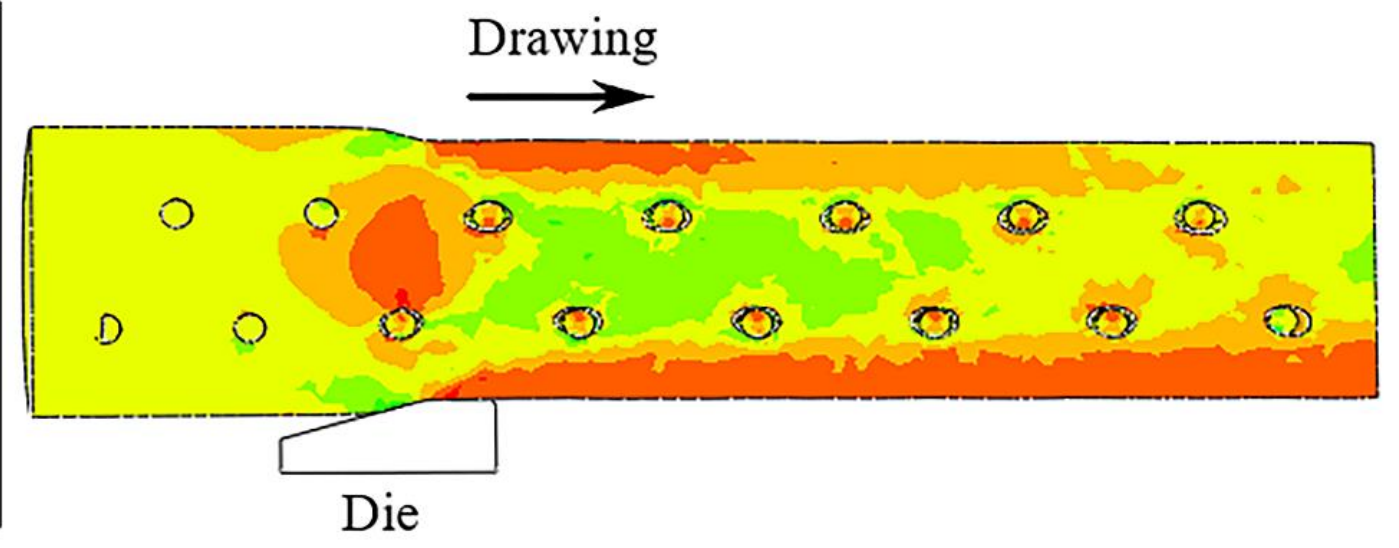

Figure 5. Stress distribution in drawing.

Figures 5 and 6 show the equivalent stresses and equivalent deformations of the helical carbon fiber composite bar during the drawing process. From Figure 5, it can be seen that the stress in the S33 direction (axial) gradually increases from the entrance end of the die (reduction zone) to the exit end (sizing zone), and the axial stress is greatest in the center of the deformation region. Figure 6 shows that the axial plastic deformation first appears in the center of the deformation region, and the first deformation region gradually moves toward the surface at a certain angle, which is consistent with the stress-strain distribution law during the drawing [30]. 

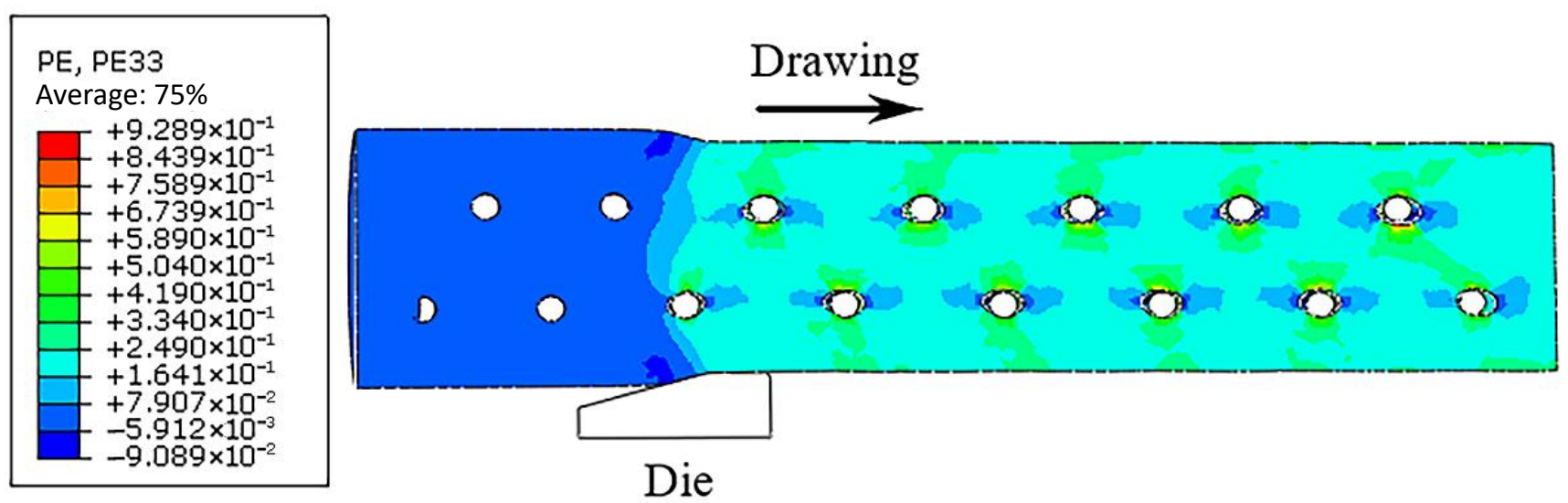

Figure 6. Strain distribution in drawing.

Through the above analysis, it was found that the finite element simulation results are in good agreement with the theoretical results, thus verifying the reliability of the finite element model established in this paper.

From the stress and strain distributions in Figures 5 and 6, it can be seen that the surface of the composite bar is affected by friction during drawing, and the stress distribution between the inner and outer layers is uneven, resulting in different degrees of deformation of the inner and outer layers. Therefore, in the process of deformation, the outer layer of the composite bar is slower than the inner layer along the axial flow rate to produce additional tensile stresses, and the inner layer has additional compressive stresses that need to be balanced with it. When the bar passes through the drawing die, the material is still in the elastic deformation stage, and under the action of elastic after-effect, the outer layer is shortened more than the inner layer; however, the integrity of the material prevents this free deformation, which generates the existence of tensile stresses in the outer layer of the material and compressive in the inner layer. The reason for residual stresses is mainly due to the uneven deformation of the inner and outer layers of the material during the drawing process. The outer layer of metal is subjected to larger shear deformation and bending deformation than the inner layer, the metal flow rate along the axial direction is slower in the outer layer than the inner layer. Due to the difference in flow rate between the inner and outer metal, pits often appear at the end of the bar after drawing. This pattern can also be found in the distribution of the velocity and displacement in Figures 7 and 8.
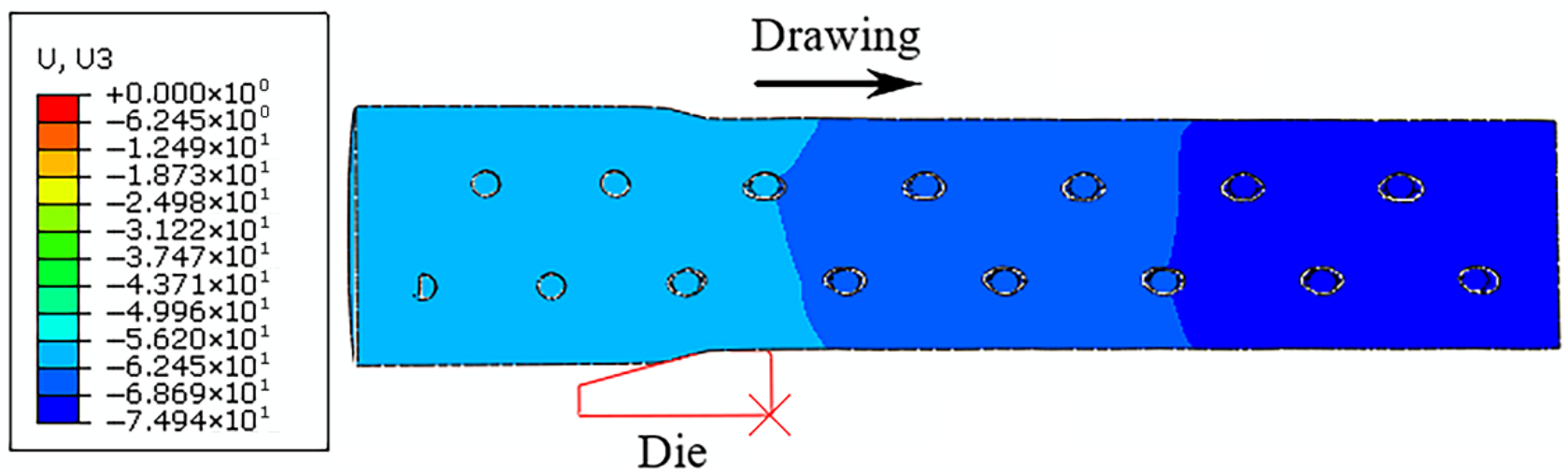

Figure 7. Displacement distribution (U3) in drawing. 

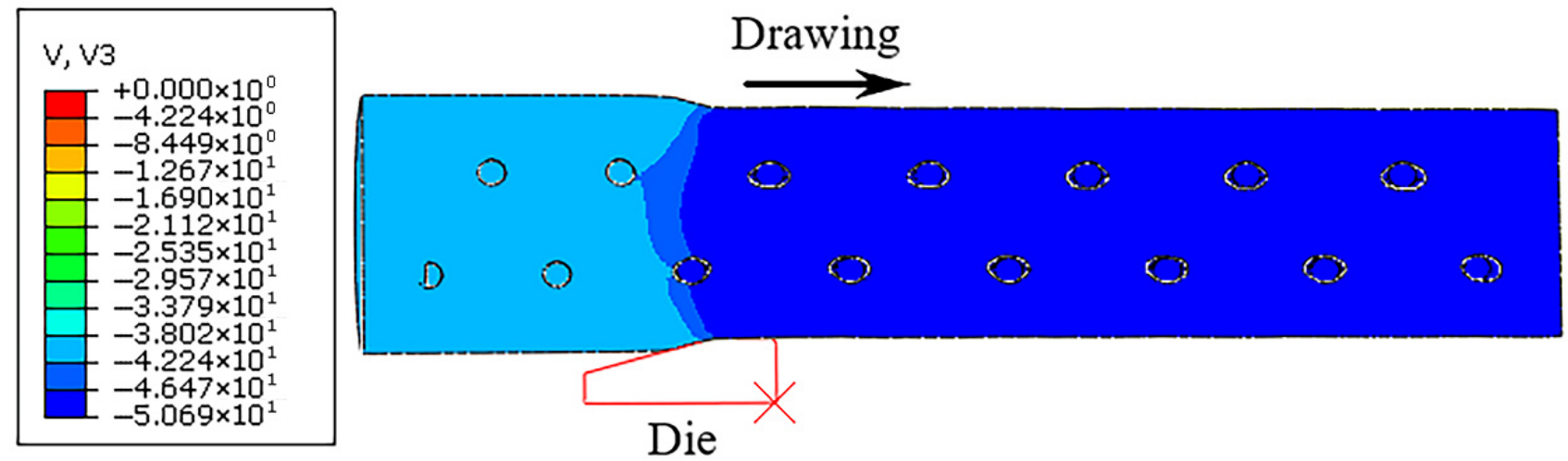

Figure 8. Velocity distribution (V3) in drawing.

\subsubsection{Analysis of Velocity and Displacement in the Drawing Deformation of Composite}

Figure 7 shows the axial distribution of displacement field of helical carbon fiber composite bar drawing, from which it can be seen that the degree of deformation is increasing as the incremental steps keep increasing. Figure 8 shows the axial distribution of velocity field in the drawing of the helical carbon fiber composite bar, from which it can be seen that the flow of each part, in the drawing process, the flow velocity in the central region of the bar is larger than that of the outer layer, and the result is that the crater appears at the end of the bar after drawing, which is also consistent with the actual situation, and verifies the validity of the model.

\subsection{Experimental Results}

The experimentally prepared composite round bar had a size of Ø20 $\mathrm{mm} \times 240 \mathrm{~mm}$. According to the drawing equipment, the composite bar billet needs to be turned and processed first, so that the billet can pass through the mold and be fixed by the jaws, and then draw. The tapered link between the two sections with different diameters is conducive to smooth drawing, otherwise vertical steps will lead to pulling fractures. After finishing the turning process, the surface of the specimen is cleaned to remove surface oil, impurities, etc., so that the surface is clean.

During the drawing, 45\# mechanical oil was used for lubrication in order to make the metal flow deformation evenly, and at the same time to improve the product surface quality and reduce the wear on the mold. After drawing, the surface of the specimen was smooth and clean, without defects such as surface cracks; however, there was a certain degree of bending of the specimen after drawing, and the specimen after drawing is shown in Figure 9.

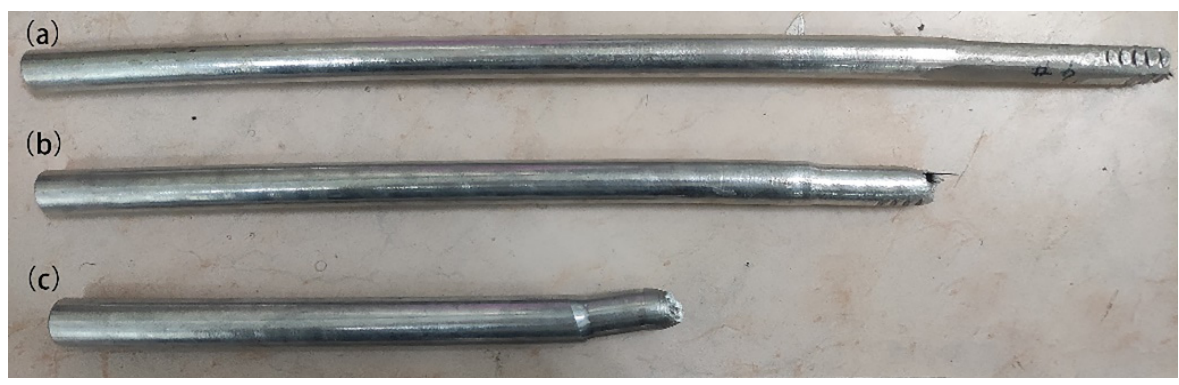

Figure 9. Sample after drawing: (a) Ø15 mm; (b) Ø16 mm; (c) Ø18 mm.

The length of the helical carbon fiber composite round bar of $\varnothing 20 \mathrm{~mm} \times 150 \mathrm{~mm}$, after five passes of drawing, is compared with the simulated results, and the length results calculated by using the volume invariance formula are shown in Table 4; since the simulated model is $1 / 3$ of the length of the test, the results are taken as 3 times the length. Figure 10 shows that both the test and simulation results after drawing are higher than the theoretical 
calculation results. The main reason for this analysis is that the theoretical calculation is only a simple mathematical geometric transformation, and the volume will not change, while the deformation in the test and simulation is complex, and the volume will increase after deformation due to the gap defects and tail craters that appear inside the deformed material; thus, the measured length also increases. The gap near the carbon fiber bundle in the simulation is more obvious, and the sliding of the center aluminum rod leads to the original aluminum rod filled part into a large gap. This results in the simulation results of the length after deformation being large, and the simulation directly taking 3 times the result value may to some extent directly expand the volume of some voids by 3 times, which may not match the actual volume. Compared with the simulation, the test specimen is not strictly controlled. The initial length of the drawn specimen was $150 \mathrm{~mm}$, and there was a slope section, so the drawn specimen was long. Moreover, due to the fact that each specimen was not exactly the same, as well as the fact that there were measurement errors and gap defects after drawing, the actual length after drawing was greater than the simulation and theoretical calculation value.

Table 4. Comparison of composite length from drawing experiments, simulations, and theoretical calculations.

\begin{tabular}{cccccc}
\hline Drawing Pass & 1st & 2nd & 3rd & 4th & 5th \\
\hline Drawing experiments $/ \mathrm{mm}$ & 194.3 & 249.6 & 289.1 & 322.7 & 382.5 \\
Simulations $/ \mathrm{mm}$ & 188.5 & 239.6 & 275.2 & 317.9 & 366.8 \\
Theoretical calculations $/ \mathrm{mm}$ & 185.2 & 234.4 & 266.7 & 306.1 & 355.0 \\
\hline
\end{tabular}

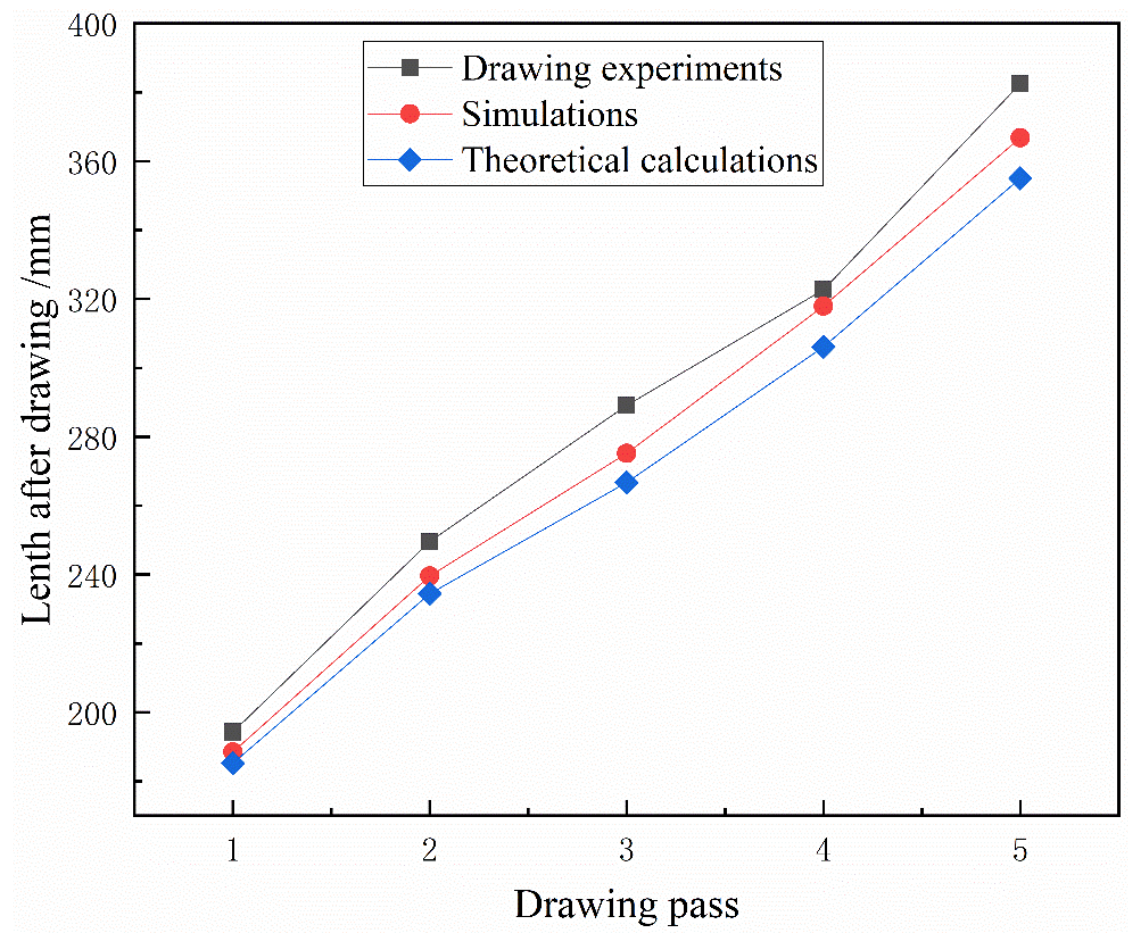

Figure 10. Comparison of length results after drawing of composite.

\subsection{Analysis of the Deformation Pattern of Helical Carbon Fiber in Drawing}

The deformation pattern of the composite reinforced phase helical carbon fiber before and after drawing can be obtained by using the finite element analysis [31]. Although the total length of carbon fiber does not change before and after drawing, the carbon fibers achieve the effect of simultaneous deformation and elongation with the aluminum matrix through the change of helical morphology. The nominal diameter of the helix gradually 
decreases, the pitch increases, and the helix inclination angle increases. Figure 11 shows the changes of helical carbon fiber before and after drawing.

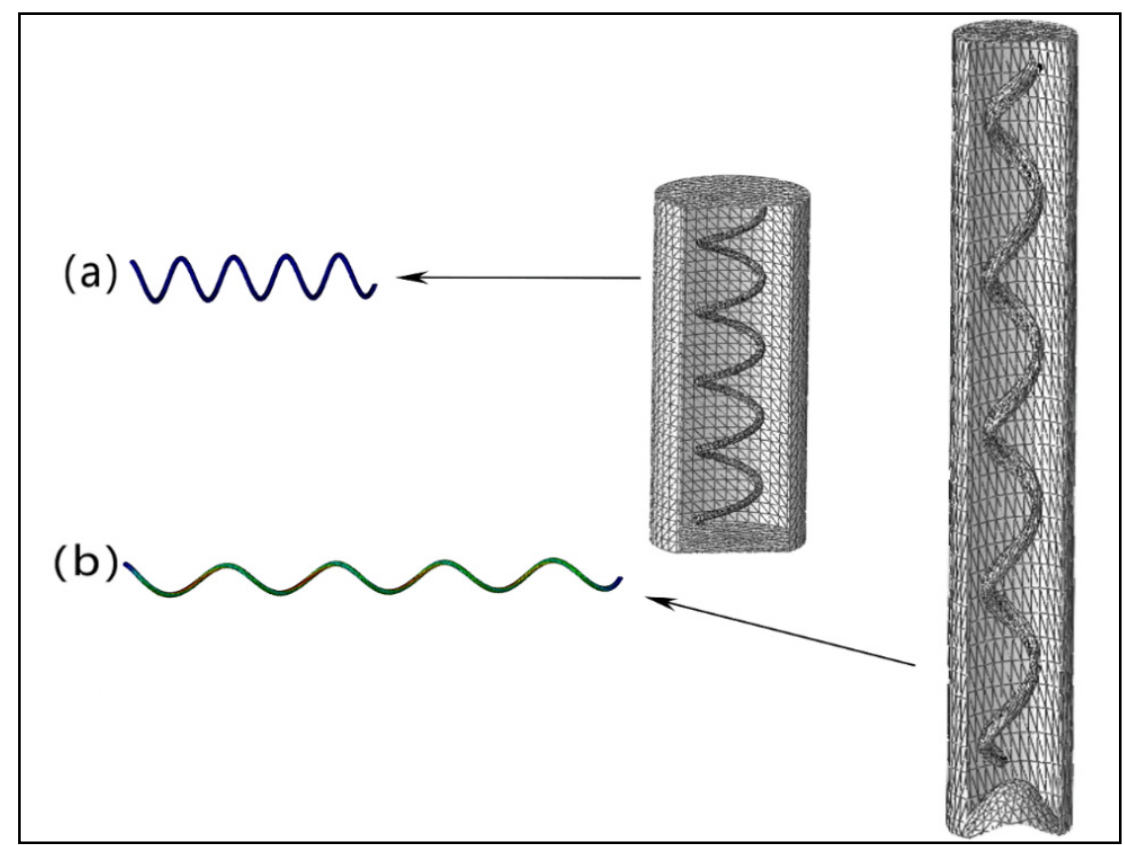

Figure 11. Comparison of spiral carbon fiber before and after drawing: (a) before drawing; (b) after drawing.

When the composite material is deformed by drawing, the drawing die transfers the compressive stress to the helical carbon fiber through the aluminum matrix, so the helical carbon fiber is subjected to the compressive stress from the aluminum matrix; however, the carbon fiber is helically arranged in the aluminum matrix, so the compressive stress on the carbon fiber during the deformation process is not completely perpendicular to a horizontal plane, but is also helically distributed, because the carbon fiber is perpendicular to the helical axis, as shown in Figure 12.

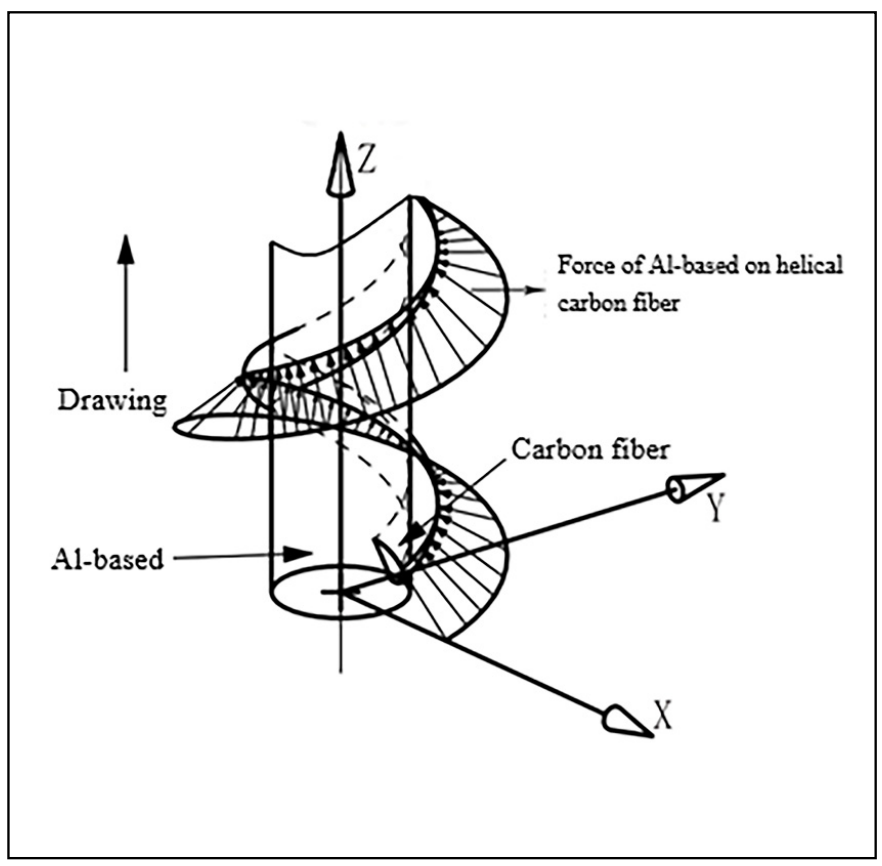

Figure 12. Force distribution of aluminum matrix on carbon fiber along the helix. 


\subsection{Influence of Processing Rate on Deformation of Composite}

\subsubsection{Effect on Deformation of Al-Based Composite}

The amount of pass deformation has an important influence on the deformation of matrix and reinforcing phase. The experimental design of five-pass deformation is mainly based on the consideration of the elongation limit of helical carbon fiber and the reduction of damage to the carbon fiber. It was found that the carbon fiber remained well integrated after five-pass drawing, and there was almost no fracture damage; however, the fracture degree of the central aluminum bar was obvious. In order to further improve the product quality of composite after drawing, the drawing was adjusted to observe the deformation pattern of the matrix and reinforced phase. The adjusted main drawing parameters are shown in Table 5.

Table 5. Main drawing parameters for the two experimental groups.

\begin{tabular}{cccc}
\hline Group & Total Processing Rate/\% & Pass Deformation/\% & Die Angle/ $^{\circ}$ \\
\hline Test 1 & $58(\varnothing 20 \rightarrow \varnothing 13)$ & $12 \sim 21$ & 15 \\
Test 2 & $58(\varnothing 20 \rightarrow \varnothing 13)$ & $5 \sim 6.3$ & 8 \\
\hline
\end{tabular}

Test 1 is a five-pass of drawing, and test 2 is to adjust the drawing with $0.5 \mathrm{~mm}$ reduction in each pass. It can be found from test 2 that reducing the processing rate of passes and decreasing the die angle have effects on the Al-based flow and deformation. As shown in Figure 13a,c,e show the center section, tail crater, and post-drawing specimen after five-pass drawing, and Figure $13 \mathrm{~b}, \mathrm{~d}$, $\mathrm{f}$ show multi-pass drawing. The comparison of Figure 13a-d shows that the center aluminum bar has almost no fracture in the previous drawing (before Ø18) after the low processing rate and multi-pass drawing, and the deformation state of the center aluminum bar was better than that of the five-pass drawing, while it also showed fracture in the subsequent drawing. In addition, after decreasing the processing rate and die angle of the passes, the difference between the surface and inner metal flow rate is also reduced, and the deformation is more uniform, which shows that the pit at the end of the substrate is not as obvious as in the five-pass drawing. The comparison of Figure 13e,f shows that the specimens have some bending after the five-pass drawing, while there is almost no bending after the multi-pass drawing, which again indicates that the adjusted multi-pass drawing regime is beneficial to the uniform deformation of the composites.

Figure 13 shows that adjusting the drawing has a great influence on the quality of the processed specimen. With the same total processing rate, the five-pass drawing increases the processing rate and die angle compared to the multi-pass drawing, which leads to the increase of the drawing force and the internal drawing stress, thus leading to the fracture of the central aluminum bar. By increasing the die angle, the outer aluminum substrate is subjected to greater friction and the metal flows more slowly than in the center; thus, the crater formed at the end is also more obvious. In addition, the greater the degree of deformation in a single pass, the more obvious the uneven deformation of the specimen is. When passing through the drawing die, the surface layer metal flows at different rates, and the side that flows faster bends to the slower side, and the drawn specimen retains its bent state without straightening.

\subsubsection{Effect on Helical Carbon Fiber}

Figure 14 shows the carbon fiber pitch increase and simulation results under two drawing processes. The maximum difference between test 2 and simulation results is also within $1 \mathrm{~mm}$, which is reflected in $\varnothing 18 \mathrm{~mm}$ when the test value is $0.9 \mathrm{~mm}$ lower than the simulation results, while the results of $\varnothing 16 \mathrm{~mm}$ and $\varnothing 15 \mathrm{~mm}$ are very close. Overall, the values of the simulated results are within the range of the two test results, and since the instability of the test results, as well as the overall difference, are within $1 \mathrm{~mm}$, which is still very small in practice, it can be considered that the test and simulated results are 
basically the same, which verifies the deformation trend of increasing pitch after carbon fiber drawing deformation.

a)

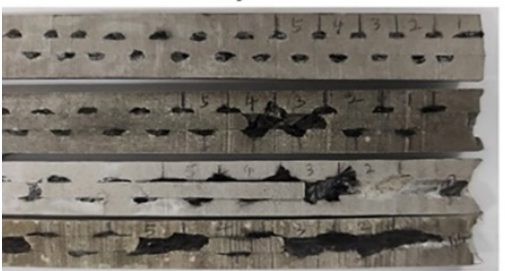

c)

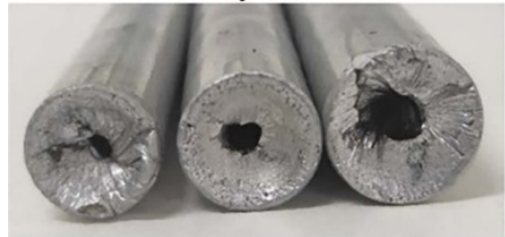

e) b)

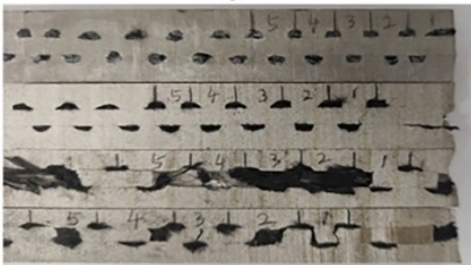

d)
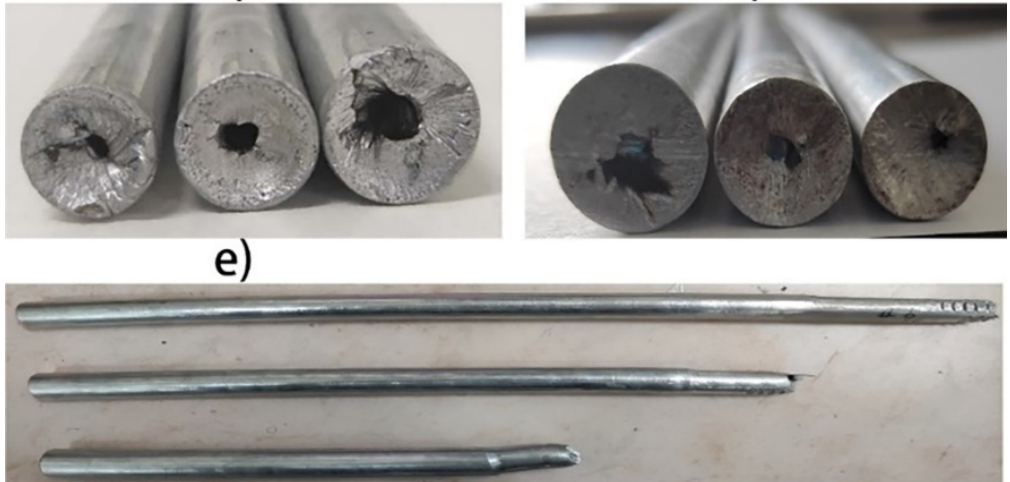

f)

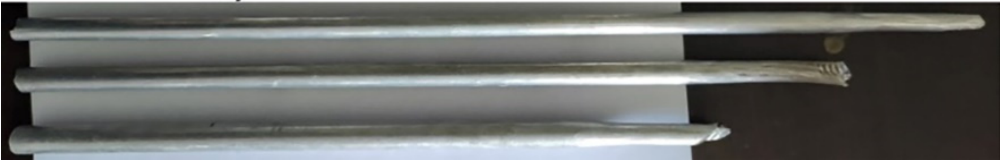

Figure 13. Comparison of specimens after different drawing: (a) center section of five-pass drawing; (b) center section of multi-pass drawing; (c) tail crater of five-pass drawing; (d) tail crater of multipass drawing; (e) post-drawing specimen after five-pass drawing; (f) post-drawing specimen after multi-pass drawing.

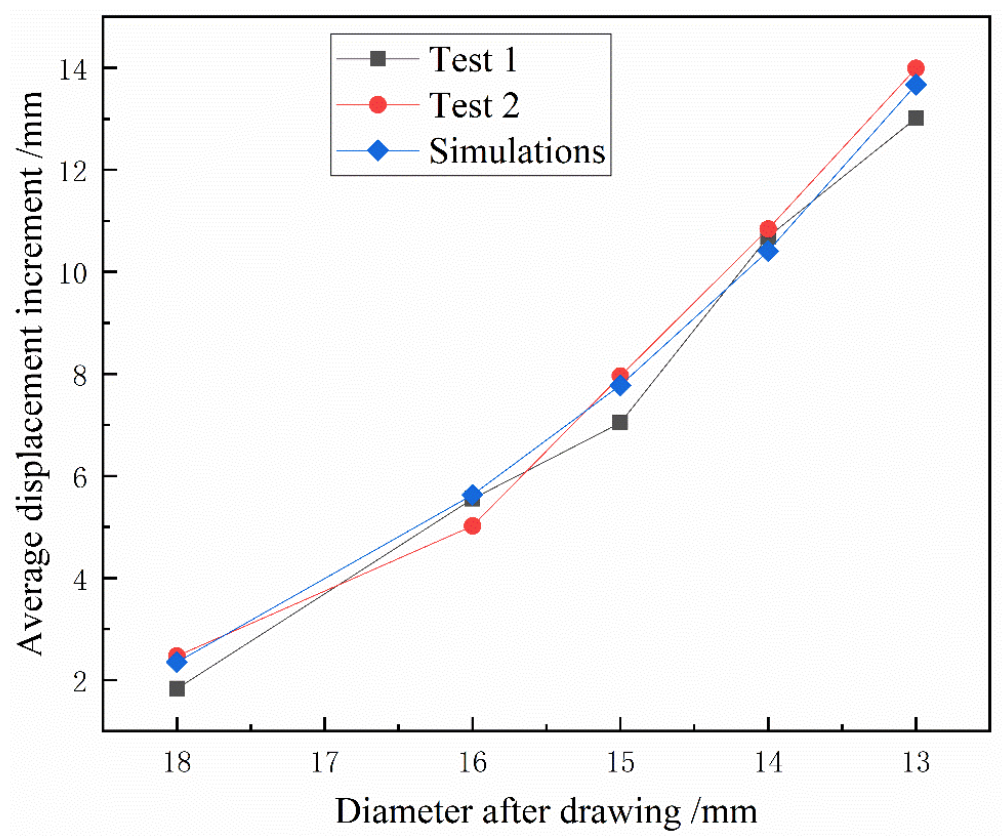

Figure 14. Average axial displacement increments of carbon fibers under different drawing processes (test 1 , test 2 and simulations). 
By comparison of tests and simulation, it can be found that, when drawing, the base metal drives the helical carbon fiber to deform together, and the composite is elongated. The helical carbon fiber continuously elongated and twisted with the matrix deformation, and the deformation results are reflected in the increase of pitch and decrease of diameter, and can maintain the integrity after deformation.

The test results show that the prepared composites can be plasticized to a certain extent, and compared to straight carbon fiber reinforced metal matrix composites, even with a processing rate of only $19 \%$ (i.e., drawing from $\varnothing 20 \mathrm{~mm}$ to $\varnothing 18 \mathrm{~mm}$ ), the elongation of plasticizable processing is well improved, while ensuring the quality and performance of the composites. The elongation of the processing reaches $23.5 \%$ when the composite is drawn from $\varnothing 20 \mathrm{~mm}$ to $\varnothing 18 \mathrm{~mm}$, while the elongation of carbon fiber is only about $1.5 \%$, and this plastic processing effect cannot be achieved at all by using straight carbon fiber. By adjusting the preparation and processing process, the performance of the composite as well as the plastic processing performance can be improved.

\subsection{Effect of Different Drawing Parameters on Drawing Force}

Under the conditions that the die size is 20-18, the friction coefficient $f=0.1$ and the drawing speed $v=50 \mathrm{~mm} / \mathrm{s}$, the die angle is changed and set to $3^{\circ}, 5^{\circ}, 7^{\circ}, 9^{\circ}, 12^{\circ}$ and $15^{\circ}$. The drawing force on the head of the helical carbon fiber aluminum bar during the drawing is equal in size and opposite in direction to the component force $T x$ of the interaction force between the drawing die and the helical carbon fiber aluminum bar along the drawing direction. Therefore, $T x$ can be extracted in the post-processing file to analyze the variation of the drawing force during the drawing.

Figure 15 shows the change of drawing force during the drawing when the die angle $\alpha=9^{\circ}$. As the helical carbon fiber aluminum bar undergoes compression deformation in the compression zone of the die, the drawing force starts to rise rapidly, and when its head passes through the die exit, the drawing force fluctuates up and down in a small range and enters the stable drawing stage. As the tail part leaves the die, the drawing force decreases to 0 , and the whole drawing process ends.

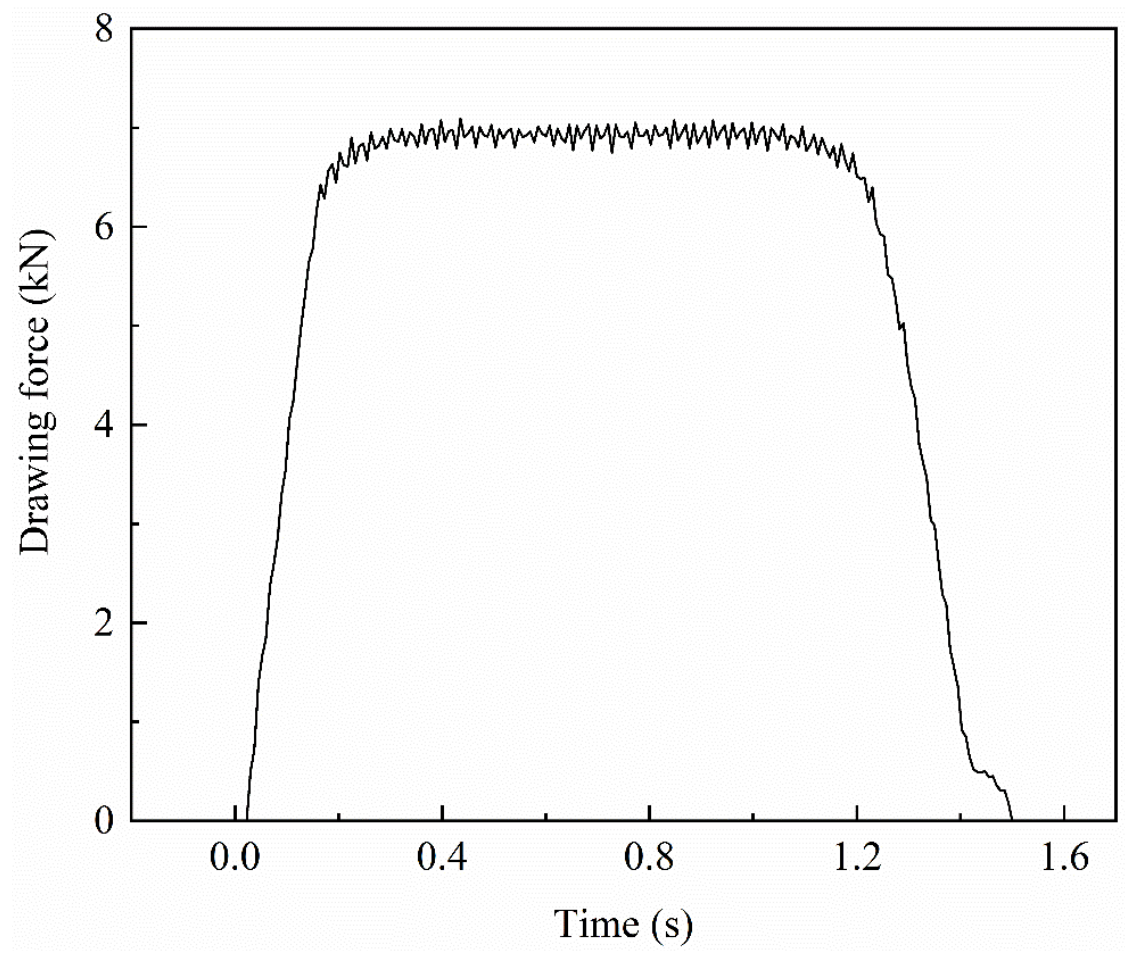

Figure 15. Drawing force change curve during the drawing process of carbon fiber aluminum bar. 
The average value of the stabilization phase of the drawing force during the drawing process is recognized as the stable drawing force, and the effect of different die angles on the stable drawing force is shown in Figure 16. It can be seen that, as the die angle increases, the drawing force decreases and then increases, reaching the minimum value at $7^{\circ}$. Therefore, under the same conditions, the most suitable value of die angle is $7^{\circ}$.

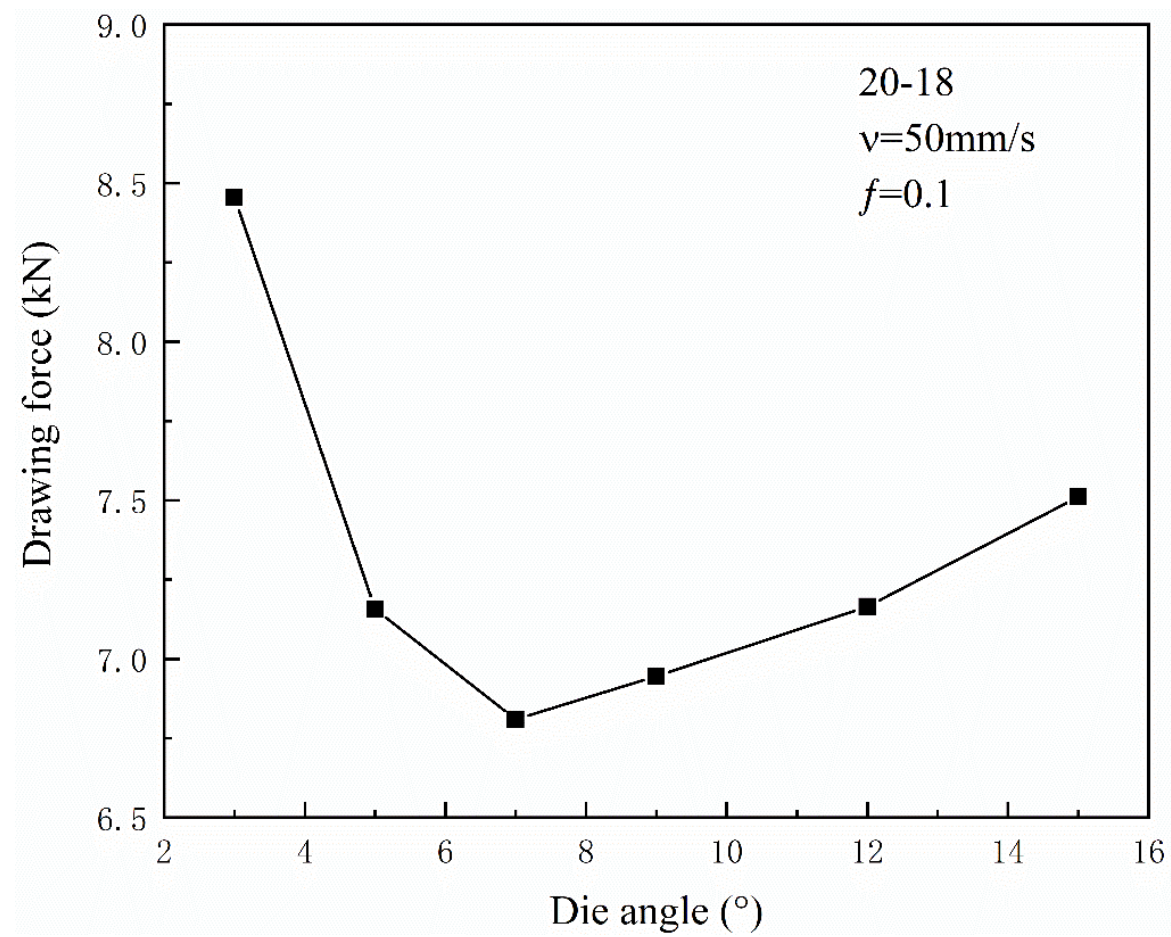

Figure 16. The relationship curve between drawing force and drawing die angle.

In summary, when the die angle increases, although the frictional stress increases with the deformation, the total contact area decreases, so there exists an optimal die angle that minimizes the drawing resistance.

\subsection{Interface of Carbon Fibers and Al-Matrix}

Figure 17 shows the quality of the connection between the carbon fiber and the aluminum matrix. Due to the poor wettability between the carbon fiber and the aluminum matrix, complete infiltration did not occur. The interface bond between the carbon fiber and the aluminum matrix is a non-metallurgical bond.

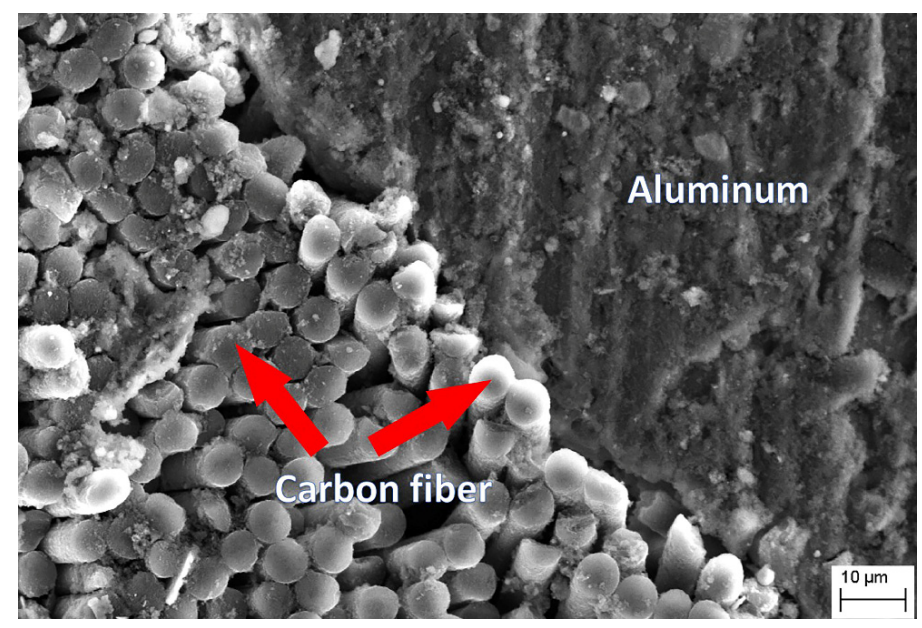

Figure 17. SEM image of the interface between carbon fiber and aluminum matrix. 


\section{Conclusions}

(1) Through reasonable preparation and processing design, composite structural materials with a certain processing rate can be obtained. The helical carbon fiber reinforced aluminum matrix composite designed and prepared in this paper has a total deformation of $58 \%$ after five-pass drawing and an average elongation of $18.9 \%$ in a single pass, while the elongation of carbon fiber is only about $1.5 \%$, and it is impossible to achieve this plastic processing effect by using straight carbon fiber.

(2) The results of the experiment and simulation of the drawing process show that the addition of helical carbon fiber hardly changes the overall flow law of the material during the deformation process, and the stress-strain is still in accordance with the drawing and forming theory, except that there are some changes in the material deformation and stress distribution around the helical carbon fiber, which causes local stress concentration near the helical carbon fiber. The presence of helical carbon fiber will impede the flow deformation of the aluminum matrix and change the metal flow direction locally.

(3) Compared to the disadvantage of straight continuous long carbon fiber reinforced aluminum matrix composites which are not conducive to plastic processing, helical carbon fiber reinforced aluminum matrix composites can achieve large deformation and high strength. The deformation of the helical carbon fiber is limited by the aluminum matrix and follows the movement of the aluminum matrix during the deformation process. During the deformation process, the carbon fiber are subjected to pressure from the aluminum matrix, and this pressure also follows the helical arrangement of carbon fiber, which gradually flattens and twists in the drawing direction under the action of the pressure on both sides of the carbon fiber, and the tensile force along the drawing direction.

(4) According to the results of test and simulation, we can find the deformation law of helical carbon fiber in the drawing, that is, the helical diameter decreases and the pitch increases after drawing. By simulation, when the friction coefficient $f=0.1$ and the drawing speed $v=50 \mathrm{~mm} / \mathrm{s}$, the die angle is changed to $3^{\circ}, 5^{\circ}, 7^{\circ}, 9^{\circ}, 12^{\circ}$ and $15^{\circ}$, and the drawing force decreases and then increases as the die angle increases, and reaches the minimum value at $7^{\circ}$. Therefore, under the same conditions, the best value of die angle is $7^{\circ}$.

Author Contributions: Conceptualization, J.L. and C.W.; methodology, J.L.; software, J.L.; validation, J.L. and W.T.; formal analysis, Z.Z.; investigation, J.L.; resources, J.L.; date curation, Z.Z.; Writing—original draft preparation, J.L.; Writing—review \& editing, C.W. and W.T; visualization, J.L.; supervision, J.L.; project administration, J.L.; funding acquisition, Z.Z. All authors have read and agreed to the published version of the manuscript.

Funding: This work is supported by the National Natural Science Foundation of China with Grant (No. 51274038).

Institutional Review Board Statement: Not applicable.

Informed Consent Statement: Not applicable.

Data Availability Statement: The data presented in this study are available on request.

Conflicts of Interest: The authors declare no conflict of interest.

\section{References}

1. Gupta, M. Metal Matrix Composites-The Way Forward. Appl. Sci. 2020, 10, 3000. [CrossRef]

2. Tang, S.; Ummethala, R.; Suryanarayana, C.; Eckert, J.; Prashanth, K.G.; Wang, Z. Additive Manufacturing of Aluminum-Based Metal Matrix Composites-A Review. Adv. Eng. Mater. 2021, 23, 2100053. [CrossRef]

3. Shirvanimoghaddam, K.; Hamim, S.U.; Karbalaei Akbari, M.; Fakhrhoseini, S.M.; Khayyam, H.; Pakseresht, A.H.; Ghasali, E.; Zabet, M.; Munir, K.S.; Jia, S.; et al. Carbon fiber reinforced metal matrix composites: Fabrication processes and properties. Compos. Part A Appl. Sci. Manuf. 2017, 92, 70-96. [CrossRef]

4. Miranda, A.T.; Bolzoni, L.; Barekar, N.; Huang, Y.; Shin, J.; Ko, S.; McKay, B.J. Processing, structure and thermal conductivity correlation in carbon fibre reinforced aluminium metal matrix composites. Mater. Des. 2018, 156, 329-339. [CrossRef]

5. Davis, W.R.; Slawson, R.J.; Rigby, G.R. An unusual form of carbon. Nature 1953, 171, 756. [CrossRef] 
6. Chak, V.; Chattopadhyay, H.; Dora, T.L. A review on fabrication methods, reinforcements and mechanical properties of aluminum matrix composites. J. Manuf. Process. 2020, 56, 1059-1074. [CrossRef]

7. Sha, J.; Lü, Z.; Sha, R.; Zu, Y.; Dai, J.; Xian, Y.; Zhang, W.; Cui, D.; Yan, C. Improved wettability and mechanical properties of metal coated carbon fiber-reinforced aluminum matrix composites by squeeze melt infiltration technique. Trans. Nonferrous Met. Soc. China 2021, 31, 317-330. [CrossRef]

8. Celentano, D.J.; Palacios, M.A.; Rojas, E.L.; Cruchaga, M.A.; Artigas, A.A.; Monsalve, A.E. Simulation and experimental validation of multiple-step wire drawing processes. Finite Elem. Anal. Des. 2009, 45, 163-180. [CrossRef]

9. Wang, D.H.; Ramulu, M.; Arola, D. Orthogonal cutting mechanisms of graphite epoxy composite. Part 1 unidirectional laminate. Int. J. Mach. Tools Manuf. 1995, 35, 1623-1638. [CrossRef]

10. Wang, D.H.; Ramulu, M.; Arola, D. Orthogonal cutting mechanisms of graphite epoxy composite. Part 2 multi directional laminate. Int. J. Mach. Tools Manuf. 1995, 35, 1639-1648. [CrossRef]

11. Rao, G.V.G.; Mahajan, P.; Bhatnagar, N. Three-dimensional macro-mechanical finite element model for machining of unidirectionalfiber reinforced polymer composites. Mater. Sci. Eng. A 2008, 498, 142-149. [CrossRef]

12. Burks, B.M.; Armentrout, D.L.; Baldwin, M.; Buckley, J.; Kumosa, M. Hybrid composite rods subjected to excessive bending loads. Compos. Sci. Technol. 2009, 69, 2625-2632. [CrossRef]

13. Očenášek, J.; Ripoll, M.R.; Weygand, S.M.; Riedel, H. Multi-grain finite element model for studying the wire drawing process. Comput. Mater. Sci. 2007, 39, 23-28. [CrossRef]

14. Norasethasopon, S.; Yoshida, K. Finite-element simulation of inclusion size effects on copper shaped-wire drawing. Mater. Sci. Eng. A 2006, 422, 252-258. [CrossRef]

15. Rauchs, G.; Thomason, P.F.; Withers, P.J. Implications of interface friction for crack growth in fibre-reinforced metal matrix composites by three-dimensional finite element modelling. Int. J. Fract. 2004, 125, 281-305. [CrossRef]

16. Tang, K.K.; Li, Z.X.; Wang, J. Numerical simulation of damage evolution in multi-pass wire drawing process and its applications. Mater. Des. 2011, 32, 3299-3311. [CrossRef]

17. Chang, X.; Xu, Q.; Lv, J.; Xu, L.; Zhu, Z.; Liu, S.; Liu, X.; Qin, J. Bioinspired 3D helical fibers toughened thermosetting composites. Compos. Part B Eng. 2021, 216, 108855. [CrossRef]

18. Liang, J.; Wu, C.; Ping, H.; Wang, M.; Tang, W. Surface Pretreatment and Fabrication Technology of Braided Carbon Fiber Rope Aluminum Matrix Composite. Metals 2020, 10, 1212. [CrossRef]

19. Junjia, Z.; Shichao, L.; Hang, C.; Yiping, L.; Qiushi, C.; Yong, D.; Tongmin, W.; Tingju, L. Surface pretreatment and fabrication technology of woven carbon fiber cloth aluminium alloy matrix composite. Mater. Sci. Forum 2015, 816, 3-8.

20. Weng, L.T.; Poleunis, C.; Bertrand, P.; Carlier, V.; Sclavons, M.; Franquinet, P.; Legras, R. Sizing removal and functionalization of the carbon fiber surface studied by combined TOF SIMS and XPS. J. Adhes. Sci. Technol. 1995, 9, 859-871. [CrossRef]

21. Zhang, J.; Liu, S.; Lu, Y.; Dong, Y.; Li, T. Fabrication process and bending properties of carbon fibers reinforced Al-alloy matrix composites. J. Mater. Process. Technol. 2016, 231, 366-373. [CrossRef]

22. Xue, Y.; Chen, W.; Zhao, Q.; Fu, Y. Electroless carbon fibers: A new route for improving mechanical property and wettability of composites. Surf. Coat. Technol. 2019, 358, 409-415. [CrossRef]

23. Hou, J.P.; Wang, Q.; Yang, H.J.; Wu, X.M.; Li, C.H.; Li, X.W.; Zhang, Z.F. Microstructure evolution and strengthening mechanisms of cold-drawn commercially pure aluminum wire. Mater. Sci. Eng. A 2015, 639, 103-106. [CrossRef]

24. Alvar, E.N.; Mohandesi, J.A. Fatigue damage accumulation in cold-drawn patented steel wire under variable loading. Mater. Des. 2010, 31, 2018-2024. [CrossRef]

25. Toribio, J.; González, B.; Matos, J.C. Fatigue and fracture paths in cold drawn pearlitic steel. Eng. Fract. Mech. 2010, 77, 2024-2032. [CrossRef]

26. Lu, P.; Cui, F.S.; Tan, M.J. A theoretical model for the bending of a laminated beam with SMA fiber embedded layer. Compos. Struct. 2009, 90, 458-464. [CrossRef]

27. Yusof, N.F.M.; Ripin, Z.M. A technique to measure surface asperities plastic deformation and wear in rolling contact. Wear 2016, 368-369, 496-504. [CrossRef]

28. Biba, N.; Rezvykh, R.; Kniazkin, I.; Brabazon, D.; Naher, S.; Ahad, I.U. Coupled modelling of aluminium profiles extrusion and product quality improvement by means of simulation. AIP Conf. Proc. 2017, 1896, 140010.

29. Slepyan, L.I.; Krylov, V.I.; Parnes, R. Helical inclusion in an elastic matrix. J. Mech. Phys. Solids 2000, 48, 827-865. [CrossRef]

30. Zhu, Y.K.; Chen, Q.Y.; Wang, Q.; Yu, H.Y.; Li, R.; Hou, J.P.; Zhang, Z.J.; Zhang, G.P.; Zhang, Z.F. Effect of stress profile on microstructure evolution of cold-drawn commercially pure aluminum wire analyzed by finite element simulation. J. Mater. Sci. Technol. 2018, 34, 1214-1221. [CrossRef]

31. Chang, C.C.; Hsieh, Y.T.; Kao, C.H.; Shao, S.Y.; Hsu, C.H. Prediction of Hardness in Drawn Copper Wire by Effective Strain from Finite Element Simulation. Mater. Sci. Forum 2019, 947, 103-108. [CrossRef] 